\title{
BMJ Open Is prolonged sitting at work associated with the time course of neck-shoulder pain? A prospective study in Danish blue-collar workers
}

\author{
David M Hallman, ${ }^{1}$ Nidhi Gupta, ${ }^{2}$ Marina Heiden, ${ }^{1}$ Svend Erik Mathiassen, ${ }^{1}$ \\ Mette Korshøj, ${ }^{2}$ Marie Birk Jørgensen, ${ }^{2}$ Andreas Holtermann ${ }^{2}$
}

To cite: Hallman DM, Gupta N, Heiden M, et al. Is prolonged sitting at work associated with the time course of neck-shoulder pain? A prospective study in Danish blue-collar workers. BMJ Open 2016;6:e012689. doi:10.1136/bmjopen-2016012689

- Prepublication history and additional material is available. To view please visit the journal (http://dx.doi.org/ 10.1136/bmjopen-2016012689).

Received 18 May 2016 Revised 30 August 2016 Accepted 19 October 2016

CrossMark

${ }^{1}$ Department of Occupational and Public Health Sciences, Centre for Musculoskeletal Research, University of Gävle, Gävle, Sweden

${ }^{2}$ National Research Centre for the Working Environment, Copenhagen, Denmark

Correspondence to Dr David M Hallman; david.hallman@hig.se

\section{ABSTRACT}

Objectives: This study aimed to determine the extent to which objectively measured sitting time at work is associated with the course of neck-shoulder pain across 1 year in blue-collar workers.

Methods: Data were analysed from 625 blue-collar workers in the Danish PHysical ACTivity cohort with Objective measurements (DPHACTO) cohort study (2012-2013). Objective data on sitting time were collected at baseline using accelerometry. Self-reported pain intensity (numeric rating scale $0-10$ ) in the neckshoulder region was registered for 1 year using repeated text messages (14 in total). Linear mixed models were used to determine the relationship between per cent time in sitting at work and trajectories of neck-shoulder pain, with and without adjustment for demographic, occupational and lifestyle factors, and baseline pain intensity.

Results: More sitting time at work was associated with a faster decline in pain intensity over 12 months, as indicated by a statistically significant effect of sitting on pain trajectories in the crude $(p=0.020)$ and fully adjusted models ( $p=0.027$ ).

Conclusions: In blue-collar workers, more sitting time at work was associated with a favourable development of pain intensity over time. The relationship between sitting at work and pain needs further investigation before explicit recommendations and guidelines on sedentary behaviour among blue-collar workers can be developed.

\section{INTRODUCTION}

Neck-shoulder pain is common in the working population ${ }^{1}$ but little is known about the role of occupational factors in determining the time course of neck-shoulder pain. ${ }^{2}$ Increased knowledge about occupational factors influencing the occurrence, aggravation and alleviation of pain would support a better prevention of pain and aid in promoting recovery among workers afflicted with pain.

\section{Strengths and limitations of this study}

- Some of the strengths of this study are:

- Strength: the association between occupational sitting and musculoskeletal pain is a topical issue.

- Strength: a large, prospective study with objective measurements of time in sitting.

- Strength: monthly assessments of neck-shoulder pain for 1 year.

- One of the limitations of this study was that the exposure assessment was only conducted at baseline.

Excessive sitting is a potential occupational risk factor for neck-shoulder pain, even in occupations not typically regarded as 'sedentary', such as blue-collar work. ${ }^{1}{ }^{3}$ Crosssectional studies have documented a positive association between occupational sitting time and neck-shoulder pain, ${ }^{4-7}$ while prospective studies are sparse and show inconsistent results. ${ }^{8}$ Previous studies have mainly relied on self-reported measures of sitting, which have poor accuracy ${ }^{9}$ and precision,,${ }^{10}$ and thus may introduce biased associations between sitting and health outcomes. ${ }^{11}$ Thus, prospective studies based on objective measurements (eg, accelerometry) are needed to clarify possible causal associations between sitting at work and neck-shoulder pain. ${ }^{12}$

The majority of studies examining associations between biomechanical work exposures and self-reported pain development have assessed pain at a few points in time interspersed by long intervals. This may introduce bias since past experiences of pain are difficult to recall after some time. ${ }^{13}$ In addition, since pain severity may vary substantially over time, study designs with few measurement points may reflect the true course of pain poorly, and 
this may result in misleading relationships between exposure and pain. ${ }^{14}$ Characterising the time course (trajectory) of pain requires repeated pain assessment, preferably on a frequent basis over an adequate period of time. ${ }^{15}$

A plausible physiological explanation for a positive association between sitting and neck-shoulder pain is that a constrained sitting posture for a prolonged period of time results in sustained muscle activation, ${ }^{16-18}$ which is a presumed causal factor for neck-shoulder pain. ${ }^{19}$ Further, inactivity may affect cardiovascular and pain regulatory systems in the central nervous system. ${ }^{20-23}$ Thus, extensive sitting may lead to less effective pain modulation. On the other hand, sitting could also be expected to be associated with a favourable course of neck-shoulder pain in occupations including high physical demands, such as blue-collar work. This can be explained by sitting resulting in less exposure to biomechanical risk factors occurring during heavy work, ${ }^{7} 1224$ in addition to permitting more recovery.

The aim of the present study was to investigate the relationship between objectively measured sitting time at work and the time course (trajectory) of neck-shoulder pain across 1 year in blue-collar workers. We hypothesise that the extent of sitting time at work is associated with the trajectory of pain during this follow-up period.

\section{METHODS}

\section{Study design and population}

The current prospective study is a part of the Danish PHysical ACTivity cohort with Objective measurements (DPHACTO), aimed at investigating relationships between objectively measured physical activities at work and the time course of musculoskeletal pain in bluecollar workers. The study protocol of DPHACTO is presented in detail elsewhere. ${ }^{25}$ In brief, data collection was conducted from spring 2012 to spring 2013 at 15 Danish workplaces in three occupational sectors, namely: cleaning (four workplaces, $\mathrm{n}=120$ ), transportation (two workplaces, $\mathrm{n}=448$ ) and manufacturing (nine workplaces, $\mathrm{n}=57$ ). The initial contact and recruitment of workplaces in these sectors were performed in collaboration with a large Danish worker union. Blue-collar workers were specifically selected to minimise confounding due to socioeconomic status while obtaining a sufficient occurrence and dispersion in occupational sitting and physical activity. ${ }^{26}$ Also, the prevalence of neck-shoulder pain in blue-collar workers is generally high. ${ }^{1}$

The study consisted of two phases: (1) baseline measurements including questionnaires, health measures and objective exposure data collection, and (2) continual measurements of neck-shoulder pain over 12 months.

In total, 2107 employees from 15 companies were invited to participate. Workplaces were considered eligible if they allowed measurements during working hours. Participants were included if they reported bluecollar work as their main occupation. Workers reporting predominant white-collar work, managing position, pregnancy or allergy to adhesives were excluded. Among the 901 blue-collar workers who were considered eligible, 755 participated in objective measurement (accelerometry) at baseline, resulting in valid measures (explained below) from 662 workers. Longitudinal data on selfreported neck-shoulder pain were collected from 625 of these workers, comprising the analysed study population. The main reason for non-participation was lack of interest $(\mathrm{n}=988)$, and main reasons for exclusion were predominant white-collar work $(n=186)$ and not taking part in the objective measurements at baseline $(n=141)$.

All participants provided their written informed consent prior to participation. This study was conducted according to the Helsinki declaration, approved by the Danish data protection agency, and evaluated by the local Ethics Committee (H-2-2012-011).

\section{Procedure}

At baseline, participants filled out a short questionnaire, underwent a health check and a physical examination, and took part in objective field measurements using accelerometry (see below). They were asked to wear four accelerometers for 24 hours during 4-5 days, including at least two working days. The participants were instructed to wear the equipment during the whole measurement period, and to perform a reference measurement in upright stance for $15 \mathrm{~s}$ each day, to ensure accurate activity detection from the accelerometer signals. They were also instructed to remove the equipment if it caused any kind of discomfort. During this period, a paper diary was used by the participant to note working hours, leisure time, and time for going to bed in the evening and getting out of bed in the morning, as well as time of the reference measurements. At the end of the data collection, the equipment was returned to the research staff. After the baseline measurements, the participants were instructed to report their neckshoulder pain intensity using text messages (see below) continually over 12 months.

\section{Objective assessment of occupational sitting time}

The participants were equipped with triaxial accelerometers (Actigraph GT3X+, ActiGraph LLC, Florida, USA) attached on the thigh, dominant upper arm, hip and trunk. The devices, attachment, and the processing and analysis of the accelerometer signals are described in detail elsewhere. ${ }^{27} 28$ The accelerometers were initialised for recording and downloading of data using ActiLife software V.5.5 (ActiGraph LLC, Pensacola, Florida, USA). Data obtained from the accelerometers were processed offline and analysed using a custommade MATLAB-based software, Acti4 (The National Research Centre for the Working Environment, Copenhagen, Denmark and BAuA, Berlin, Germany). This software determines the type and duration of different physical activities and body postures (including sitting) with a high sensitivity and specificity, both in standardised and free-living conditions. ${ }^{28-31}$ 
Non-wear was identified when (a) the software detected a period longer than 90 min with zero acceleration counts, or (b) the participant reported non-wear time, or (c) artefacts or missing data were detected by visual inspection. Non-work days and time in bed were excluded from further analyses. Valid work intervals (determined from the diary) had to contain at least 4 hours/day of accelerometer wear time or $75 \%$ of the average wear time across days for the individual. Records were excluded if they had less than one recorded day. ${ }^{27}$

The occurrence of sitting periods was identified from the accelerometer outputs based on previously described procedures. ${ }^{27} 28$ The occurrence of sitting and nonsitting periods at work was identified for each measurement day, averaged across days (hour/day), and expressed as percentage of total time at work. In addition, sitting time was trichotomised using tertiles of sitting time at work to obtain three exposure groups as a means to enhance interpretation of the results. Specifically, the change in pain is presented across three categories of sitting time to allow an interpretation of the statistical interaction between continuous sitting time and changes in pain over 12 months. The range of sitting time for the tertiles was 1.6-17.1\% (low), 17.2$35.6 \%$ (middle), and 35.8-91.5\% (high).

\section{Continual assessment of neck-shoulder pain intensity}

Text messages ('SMS-Track' (https://sms-track.com/)) were used to collect repeated data on self-reported pain intensity during a 12-month period. The participant received one text message every fourth week over 12 months, starting at baseline, resulting in 14 text messages in total. The text messages were sent on Sundays, with a reminder the following day. The participants rated their peak pain intensity in the neck-shoulder region during the previous month on the numerical rating scale (NRS), which ranges from 0 ('no pain') to 10 ('worst pain imaginable'). The NRS is a valid instrument for assessment of pain severity, ${ }^{32}$ and it is recommended as a 'core outcome measure' by the 'Initiative on Methods, Measurement, and Pain Assessment in Clinical Trials'. 33

\section{Assessment of possible confounders}

A broad selection of individual and biomechanical factors were chosen a priori as potential confounders based on previous literature and theoretical assumptions concerning their possible influence on sitting behaviour and neck-shoulder pain. Age was determined from the workers' Danish civil registration numbers. Body mass index (BMI, $\mathrm{kg} / \mathrm{m}^{2}$ ) was calculated from objectively measured height $(\mathrm{cm})$ and body weight $(\mathrm{kg})$. Seniority in the current job (months) was assessed using the question: 'For how long have you had the kind of occupation that you have now?'. Lifting and carrying at work was assessed using a single item from the Danish Work Environment Cohort Survey (DWECS): 'How much of your working time do you carry or lift?', using a six-point response scale ranging from 1 ('never') to 6 ('almost all the time'). ${ }^{34}$ Change in physical work tasks over the 12-month period was assessed using a single-item question in the follow-up questionnaire: 'Have your physical tasks changed over the past year?' with two response categories ('yes' or 'no'). Psychosocial factors at work were assessed using four items from the Copenhagen Psychosocial Questionnaire (COPSOQ) ${ }^{35}$ representing two dimensions, that is, influence at work (decision authority): 'Do you have a large degree of influence concerning your work?'; 'Can you influence the amount of work assigned to you?' and social support at work: 'Is there a good co-operation between the management and the employees?'; 'Is there good co-operation between the colleagues at work?'. The five-point response scale ranged from 1 ('always') to 5 ('never'). Based on these items, an index (scale 0-8) was computed for each dimension according to the COPSOQ manual (http://www.arbejdsmiljoforskning.dk), whereby higher numbers indicate more influence and better social support, respectively. The number of days with pain was assessed using the question 'In the past 12 months, how many days in all have you had pain or discomfort in the neck/shoulders?' with six response categories ranging from ' 0 days' to 'every day'. Intake of pain medication was assessed using the question: 'In the past 3 months, how many days have you been taking analgesics due to pain in muscles or joints?' with six response categories ranging from ' 0 days' to 'more than 60 days'.

Physical activity was assessed objectively using data from the accelerometers described above. ${ }^{29}{ }^{30}$ The total time spent in walking, climbing stairs, running and cycling was added up and expressed in percentage of total time at work and leisure, respectively. The extent (hour/day) of working with the dominant upper arm elevated $>60^{\circ}$ was estimated from the accelerometer signals according to Korshøj et al. ${ }^{31}$ Sitting time during leisure was obtained from the processed accelerometer signals, as explained above, and expressed in percentage of total leisure time.

\section{Statistical analyses}

All statistical analyses were performed using SPSS V.22 (IBM). Descriptive data are presented as mean and SD between subjects, or as frequency and percentage, where appropriate. Associations between sitting time at work and pain intensity at baseline were examined using Pearson's correlation coefficients. Differences in pain intensity at baseline between the three occupational sectors were tested statistically using one-way analysis of variance (ANOVA).

The association between sitting time at work and the 1-year time course (trajectory) of neck-shoulder pain intensity was analysed using linear mixed models. ${ }^{36}$ Subject and intercept were included as random factors, while sitting (percentage of working hours, continuous variable), time (14 measurement points over 1 year) and 
their interaction (sitting $\times$ time) were included as fixed factors, as were the covariates in the adjusted models (see below). Neck-shoulder pain intensity was the dependent variable in all models. Subjects with missing values in the repeated outcome were kept in the models. Since non-linear representations of pain trajectories did not improve model fit, the association was modelled linearly. An autoregressive covariance structure (AR1) was used to accommodate for correlations between pain intensity ratings getting weaker with time. Inspection of the residuals indicated no marked deviation from normal distribution.

The primary analysis of the association between sitting time and individual trajectories of pain consisted of three models: that is, crude model (model 1) without any additional covariates; individual factors (model 2): adjusted for age, gender and BMI; biomechanical factors: (model 3) adjusted for the covariates in model 2 and occupational sector, lifting/carrying time at work, sitting time at leisure, physical activity at work and during leisure, working with dominant arm elevated $>60^{\circ}$. To examine whether the relationship between sitting time and pain was modified by sector (ie, cleaning, manufacturing and transportation), the second primary model was rerun including a three-way interaction (sector $\times$ sitting$\times$ time). If this interaction was significant, the primary models 1, 2 and 3 were performed with stratification for occupational sector. In each model, we derived the estimates (B), SE, 95\% CIs and $\mathrm{p}$ values of the main effects of sitting and time and their interaction on pain intensity.

Three sensitivity analyses were performed to verify the robustness of the results from the primary analyses. First, the three primary models were performed with exclusion of participants having less than five valid pain responses. Second, the primary models were performed using absolute values of time in sitting (hour/day) instead of relative percentages. Third, the fully adjusted primary model was performed with additional adjustment of four additional covariates in separate models: (1) baseline pain intensity, (2) influence and social support at work, (3) pain medication and (4) selfreported change in physical work tasks across the study period.

\section{RESULTS}

\section{Descriptive information of the study population}

Descriptive data of the study population are shown in table 1 . The population consisted of 625 workers, including men $(55 \%)$ and women $(45 \%)$ between 18 and 68 years of age. The gender distribution differed between sectors, with women dominating the cleaning sector $(86 \%)$, while transportation $(96 \%)$ and manufacturing $(62 \%)$ were dominated by men.

The recorded sitting time per day was, on average, $31 \%$ at work and $53 \%$ during leisure, while physical activity occurred for $17 \%$ of the working hours and $10 \%$ of leisure time (table 1). Compliance with pain ratings via text messages was very high; from $95 \%$ response rate during baseline to $85 \%$ at the last measurement 12 months later. Ninety per cent of the study population had at least 10 valid pain responses (out of 14 requested) during the period. Almost $70 \%$ of the population reported baseline pain intensity in the neckshoulder region above 1 on the $0-10$ scale, and only $29 \%$ were completely free of pain. Seventy-five per cent reported at least 1 day with neck-shoulder pain during the past year, $25 \%$ reported more than 30 days with pain, and $17 \%$ reported more than 90 pain days.

Per cent sitting time at work was not correlated with baseline pain intensity $(\mathrm{r}=-0.01, \mathrm{p}=0.87)$. Per cent sitting time at work differed between the three occupational sectors (ANOVA: $\mathrm{F}(2,622)=88.8, \mathrm{p}<0.001$ ) with, on average, higher values in the transportation sector $(60.5 \%$, SD 14.8$)$ than in cleaning $(26.6 \%$, SD 11.6$)$ and manufacturing (29.0\%, SD 19.8).

\section{Primary analysis results on the effect of sitting at work on pain trajectories}

The results from the crude (model 1) and adjusted primary analyses (models 2 and 3) are shown in table 2. Pain intensity tended to decrease, on average, over the 12-month period, as indicated by the main effect of time. Higher sitting time at work showed a borderline significant association $(p=0.055)$ with higher overall pain intensity, as indicated by the main effect of sitting on pain in the fully adjusted model, but this trend was not present in the crude model or when adjustments for individual factors were made (model 2). More sitting time at work was associated with a faster decline in pain intensity over time (figure 1), as indicated by the significant interaction between sitting and time, which persisted after adjustment for covariates (models 2 and 3 ).

\section{Difference between occupational sectors}

The primary analysis was rerun with a three-way interaction term comprising sector, sitting at work and time, which was significant (model 3: B $-0.04,95 \%$ CI -0.006 to -0.001$)$. Stratified analyses by sector revealed no difference between sectors in the direction of the association between sitting and time, but significant estimates were only found in the transportation sector (table 3). The main effect of sitting on pain was not significant in any stratified model. The effect of time on pain showed negative estimates in the cleaning and manufacturing sectors, while positive estimates were found in the transportation sector.

\section{Sensitivity analyses}

Three sensitivity analyses were performed to verify the results from the primary analyses (corresponding model estimates are presented in online supplementary material S1-S3). When the primary models (1, 2 and 3) were resolved after exclusion of participants having less than five valid pain responses, the interaction between sitting and time remained significant in all models, and 
Table 1 Descriptive information of the Danish PHysical ACTivity cohort with Objective measurements (DPHACTO) study population at baseline

\begin{tabular}{|c|c|c|c|c|}
\hline & Valid data (n) & n (\%) & Mean & SD \\
\hline Women & 625 & $280(45)$ & & \\
\hline Sector & 625 & & & \\
\hline Cleaning & & $120(19)$ & & \\
\hline Manufacturing & & $448(72)$ & & \\
\hline Transportation & & $57(9)$ & & \\
\hline Age (years) & 625 & & 44.8 & 9.8 \\
\hline Body mass index $\left(\mathrm{kg} / \mathrm{m}^{2}\right)$ & 610 & & 27.5 & 4.9 \\
\hline Lifting and carrying at work (scale 1-6) & 622 & & 3.5 & 1.4 \\
\hline Seniority in the job (years) & 599 & & 13.2 & 10.2 \\
\hline Social support at work (scale $0-8$ ) & 429 & & 6.3 & 1.3 \\
\hline Influence at work (scale 0-8) & 429 & & 5.0 & 2.1 \\
\hline \multicolumn{5}{|l|}{ Objective exposure levels } \\
\hline Accelerometer wear time (number of working days) & 625 & & 2.6 & 1.0 \\
\hline Physical activity* at work (\% work time) & 625 & & 16.9 & 7.0 \\
\hline Physical activity* at leisure (\% leisure time) & 625 & & 9.7 & 4.2 \\
\hline Arm elevation $>60^{\circ}$ at work (hour/day) & 611 & & 0.5 & 0.4 \\
\hline Sitting time at work (hours/day) & 625 & & 2.4 & 1.7 \\
\hline Sitting time at leisure (hours/day) & 625 & & 4.6 & 1.4 \\
\hline Per cent sitting time at work (\%) & 625 & & 30.8 & 20.4 \\
\hline Per cent sitting time at leisure (\%) & 625 & & 52.6 & 12.5 \\
\hline Pain intensity at baseline (scale $0-10$ ) & 625 & & 3.1 & 2.7 \\
\hline Pain-free at baseline & 625 & $180(29)$ & & \\
\hline Number of days with pain in the past yeart (days) & 622 & & & \\
\hline $0-7$ & & $338(54)$ & & \\
\hline 8-90 & & $180(29)$ & & \\
\hline$>90$ & & $104(17)$ & & \\
\hline Pain medication in the past 3 months $\ddagger$ (days) & 622 & & & \\
\hline 0 & & $279(45)$ & & \\
\hline $1-7$ & & 206 (33) & & \\
\hline $8-30$ & & $92(15)$ & & \\
\hline$>30$ & & $45(7)$ & & \\
\hline
\end{tabular}

the CI of the effect estimates became smaller compared with the primary models without exclusion. The main effect of sitting was close to significant in model 3, but not in models 1 and 2 (see online supplementary material S1).

When the primary models (1-3) were resolved using absolute values of sitting time (hour/day) instead of percentages, the interactions between sitting and time were similar to those in the primary analyses, but the main effect of sitting was not significant in any model (see online supplementary material S2).

Inclusion of additional covariates in the primary, fully adjusted model did not change the estimates of the interaction between sitting and time markedly, neither when including baseline pain intensity, influence and social support at work, pain medication, or self-reported change in physical work tasks across the study period (see online supplementary material S3). The borderline significant main effect of sitting persisted from model 3, but it became less significant when adjusting for pain medication and for self-reported change in physical work tasks.

\section{DISCUSSION}

This study aimed to determine the relationship between objectively measured sitting time at work and the course of neck-shoulder pain over 1 year in blue-collar workers. We found that more sitting at work was associated with favourable trajectories of neck-shoulder pain (ie, reduced pain intensity over 12 months).

Prospective studies on occupational sitting and neckshoulder pain are sparse and show conflicting results. Our key finding of a negative association between objectively measured sitting time and trajectories of neck-shoulder pain intensity is in contrast to the study by Ariens et $a l^{37}$ while it corroborates the studies by Grooten $e t a l^{24}$ and Picavet et al. ${ }^{12}$ Grooten et $a l^{24}$ used a self-report to assess sitting time in 803 workers, and found that sitting for more than $75 \%$ of the working 
time was associated with a higher relative chance of being free of neck-shoulder pain after 5 years compared with sitting less. Similarly, Picavet $e t a l^{12}$ found that more self-reported time sitting at work was associated with less upper extremity pain over a 15 -year period. In contrast, Ariens et $a \hat{l}^{37}$ used video observations (ie, four 1014 min video recordings in one-fourth of the workers) to estimate sitting time in the whole sample of 977

\begin{tabular}{|c|c|c|c|c|c|}
\hline & \multirow[b]{2}{*}{ Estimate } & \multirow[b]{2}{*}{ SE } & \multirow[b]{2}{*}{$p$ Value } & \multicolumn{2}{|l|}{$95 \% \mathrm{Cl}$} \\
\hline & & & & Lower & Upper \\
\hline \multicolumn{6}{|l|}{ Model $1(n=625)$} \\
\hline Intercept & 2.976 & 0.179 & $<0.01$ & 2.624 & 3.327 \\
\hline Time & -0.020 & 0.010 & 0.053 & -0.040 & 0.000 \\
\hline Sitting & 0.000 & 0.005 & 0.966 & -0.009 & 0.010 \\
\hline $\begin{array}{l}\text { Interaction } \\
\text { (sitting×time) }\end{array}$ & -0.001 & 0.000 & 0.020 & -0.001 & 0.000 \\
\hline \multicolumn{6}{|l|}{ Model $2(n=610)$} \\
\hline Intercept & 1.280 & 0.695 & 0.066 & -0.085 & 2.645 \\
\hline Time & -0.019 & 0.010 & 0.072 & -0.039 & 0.002 \\
\hline Sitting & 0.003 & 0.005 & 0.582 & -0.007 & 0.012 \\
\hline $\begin{array}{l}\text { Interaction } \\
\text { (sitting×time) }\end{array}$ & -0.001 & 0.000 & 0.020 & -0.001 & 0.000 \\
\hline \multicolumn{6}{|l|}{ Model $3(n=595)$} \\
\hline Intercept & 3.020 & 1.084 & 0.006 & 0.891 & 5.149 \\
\hline Time & -0.019 & 0.010 & 0.065 & -0.040 & 0.001 \\
\hline Sitting & 0.012 & 0.006 & 0.055 & 0.000 & 0.025 \\
\hline $\begin{array}{l}\text { Interaction } \\
\text { (sitting×time) }\end{array}$ & -0.001 & 0.000 & 0.027 & -0.001 & 0.000 \\
\hline
\end{tabular}

\section{Model 1: unadjusted.}

Model 2: adjusted for gender, age and body mass index.

Model 3: adjusted for the covariates in model 2 and occupational sector, lifting/carrying time at work, sitting time at leisure, physical activity at work and leisure, upper arm elevation $>60^{\circ}$ at work. 'Time' indicates the 14 pain ratings over 12 months, starting at baseline; 'sitting' represents sitting time in percentage of working hours; 'interaction' indicates the effect of sitting on the rate of change in pain intensity over time. workers from different occupations. They found that sitting for more than $95 \%$ of the working time increased the risk of reporting regular or prolonged neck pain 3 years later compared with sitting very little.

To the best of our knowledge, this is the first prospective study on neck-shoulder pain using multiple accelerometers to obtain accurate and precise records of sitting time over several working days, thus minimising possible bias associated with self-reported measures of sitting. ${ }^{9-11}$

Our findings suggest that more sitting time at work has a favourable influence on the course of neck-shoulder pain in blue-collar workers. This may be explained by sitting being associated with less exposure to physically heavy work and more time for recovery, which suggests that sitting is a proxy for other risk factors for pain. ${ }^{7} 1224$ This indicates that occupational sitting is not a risk factor for enhanced neck-shoulder pain in bluecollar workers. Thus, recommendations to reduce sitting in blue-collar work may impose harmful consequences with respect to musculoskeletal health.

To account for possible confounding by biomechanical factors related to work, we adjusted for self-reported occurrence of lifting/carrying, and objectively measured physical activity and upper arm elevation. We also accounted for biomechanical exposures occurring during non-work hours, by adjusting for objectively assessed sitting and physical activity during leisure time. None of these adjustments changed the results. Overall, the association between sitting time and pain trajectories remained stable after adjustment for individual (model 2) and biomechanical factors (model 3), and even in the sensitivity analyses adjusting for psychosocial factors, baseline pain intensity, pain medication and self-reported change in physical work tasks over the study period (see online supplementary material S3).

The stratified analyses by occupational sector showed a stronger effect of sitting on pain trajectories in the transportation sector compared with the other two sectors. This suggests that occupational sector is a modifier for the relationship between sitting and pain trajectories. However, the marked gender imbalance across sectors
Figure 1 Pain trajectories in the Danish PHysical ACTivity cohort with Objective measurements (DPHACTO) study population stratified on tertiles (ie, low, middle and high) of per cent sitting time at work. The y-axis represents the mean neckshoulder pain intensity on a $0-10$ scale $(A)$, and the estimated mean neck-shoulder pain intensity (scale 0-10) according to the crude model (B). The $x$-axis represents the 14 time points over the 12 months follow-up period.
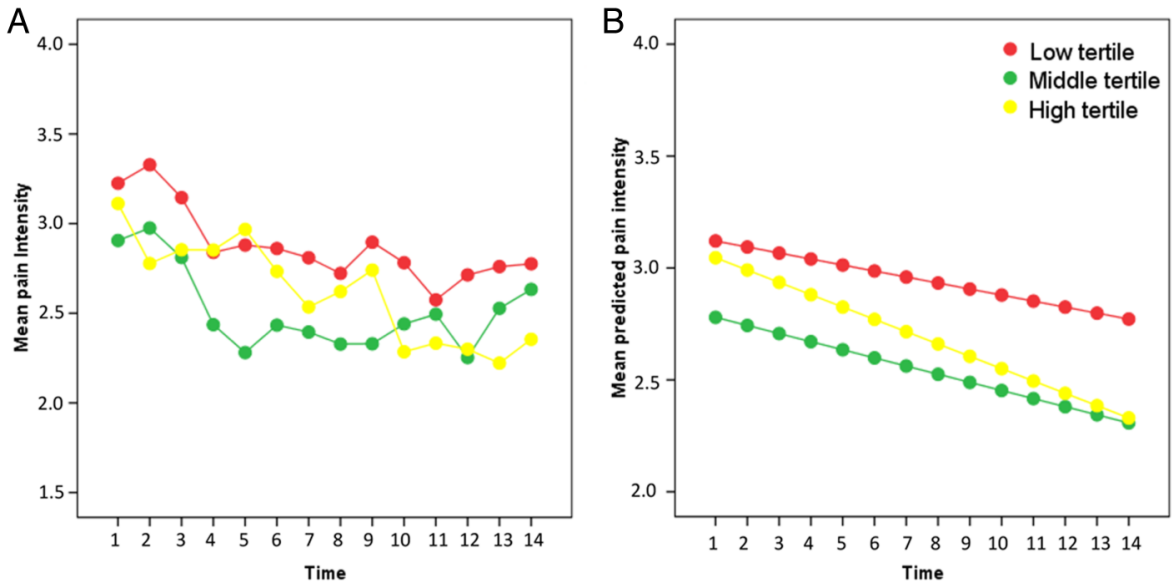
Table 3 Association between per cent sitting time at work and trajectories of neck-shoulder pain (scale 0-10), stratified by occupational sector in the Danish PHysical ACTivity cohort with Objective measurements (DPHACTO) study population

\begin{tabular}{|c|c|c|c|c|c|c|c|c|c|c|c|c|}
\hline & \multicolumn{4}{|c|}{ Cleaning $(n=120)$} & \multicolumn{4}{|c|}{ Manufacturing $(n=448)$} & \multicolumn{4}{|c|}{ Transportation $(n=57)$} \\
\hline & \multirow[b]{2}{*}{ Estimate } & \multirow[b]{2}{*}{$\begin{array}{l}\text { p } \\
\text { Value }\end{array}$} & \multicolumn{2}{|l|}{$95 \% \mathrm{Cl}$} & \multirow[b]{2}{*}{ Estimate } & \multirow[b]{2}{*}{$\begin{array}{l}\mathbf{p} \\
\text { Value }\end{array}$} & \multicolumn{2}{|l|}{$95 \% \mathrm{Cl}$} & \multirow[b]{2}{*}{ Estimate } & \multirow[b]{2}{*}{$\begin{array}{l}\mathbf{p} \\
\text { Value }\end{array}$} & \multicolumn{2}{|l|}{$95 \% \mathrm{Cl}$} \\
\hline & & & Lower & Upper & & & Lower & Upper & & & Lower & Upper \\
\hline \multicolumn{13}{|l|}{ Model $1(n=625)$} \\
\hline Intercept & 3.040 & 0.000 & 2.023 & 4.058 & 2.762 & 0.000 & 2.351 & 3.173 & 1.583 & 0.174 & -0.712 & 3.878 \\
\hline Time & -0.023 & 0.436 & -0.081 & 0.035 & -0.024 & 0.039 & -0.048 & -0.001 & 0.157 & 0.038 & 0.009 & 0.305 \\
\hline \multicolumn{13}{|l|}{ Model $2(n=610)$} \\
\hline Intercept & 2.536 & 0.131 & -0.764 & 5.836 & 0.651 & 0.441 & -1.010 & 2.313 & 0.877 & 0.687 & -3.457 & 5.212 \\
\hline Time & -0.024 & 0.417 & -0.082 & 0.034 & -0.023 & 0.055 & -0.047 & 0.000 & 0.157 & 0.038 & 0.009 & 0.305 \\
\hline Sitting & 0.011 & 0.595 & -0.030 & 0.053 & 0.005 & 0.368 & -0.006 & 0.017 & 0.017 & 0.393 & -0.023 & 0.058 \\
\hline \multicolumn{13}{|l|}{ Model $3(n=595)$} \\
\hline Time & -0.023 & 0.431 & -0.081 & 0.035 & -0.024 & 0.045 & -0.048 & -0.001 & 0.156 & 0.044 & 0.004 & 0.309 \\
\hline Sitting & 0.019 & 0.407 & -0.026 & 0.064 & 0.007 & 0.296 & -0.007 & 0.021 & 0.009 & 0.841 & -0.077 & 0.094 \\
\hline $\begin{array}{l}\text { Interaction } \\
\text { (sitting×time) }\end{array}$ & -0.001 & 0.394 & -0.003 & 0.001 & 0.000 & 0.351 & -0.001 & 0.000 & -0.004 & 0.004 & -0.006 & -0.001 \\
\hline $\begin{array}{l}\text { Significant }(p<0.05 \\
\text { Model 1: unadjuste } \\
\text { Model 2: adjusted } \\
\text { Model 3: adjusted } \\
\text { upper arm elevatio }\end{array}$ & $\begin{array}{l}\text { mates are } \\
\text { nder, age } \\
\text { covariate }\end{array}$ & $\begin{array}{l}\text { boldfac } \\
\text { and bo } \\
\text { es in } \mathrm{mc}\end{array}$ & lass & $\begin{array}{l}\text { dex. } \\
\text { lifting/ }\end{array}$ & . & 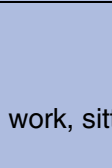 & 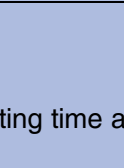 & leisu & 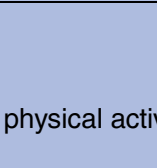 & 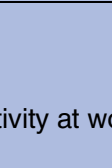 & 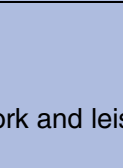 & ure, \\
\hline
\end{tabular}

may have influenced these results due to possible gender differences in sitting time patterns at work. ${ }^{26}$

The higher tertile of sitting $(n=209)$ had an average sitting time of $55 \%$ of the working hours, which is noteworthy considering that the study population consisted of blue-collar workers. Still, it is not known from this study whether the observed association with neck-shoulder pain is consistent in occupations with a higher occurrence of sitting at work. Thus, we recommend future prospective studies to investigate this association further based on objective exposure assessment in more sedentary populations, such as office workers.

The borderline significant association between sitting and neck-shoulder pain in the fully adjusted model indicated higher pain intensity, on average, with more sitting time at work. This would be in agreement with previous cross-sectional studies. ${ }^{5} 7$ However, since this main effect of sitting was present along with an interaction with time, and only observed in the fully adjusted model, it should be interpreted with caution.

\section{Methodological discussion}

This study has several methodical strengths. First, we relied on continuous objective measurements of sitting over several working days to obtain reliable and valid exposure estimates. This is important because selfreported measures of sitting may be imprecise and biased, ${ }^{9} 10$ which can lead to deceptive associations between sitting and health outcomes. ${ }^{11}$ Second, assessing pain intensity every 4 weeks over a 1 year period allowed for a precise estimation of individual pain trajectories. Third, the sample size was relatively large $(n=625)$, and thus our study was considered to be sufficiently powered to determine the association between sitting and neck-shoulder pain, even with multiple adjustments. ${ }^{25}$

There are also study limitations which may have implications for the interpretation of the results. We did not measure sitting exposure repeatedly over the 1 year period, which precludes us from inferring whether changes in sitting occurred with time, and thus whether sitting affected neck-shoulder pain in the short term. We did, however, adjust our analyses for self-reported change in physical work tasks across the 12-month period, and found that the association between sitting and pain trajectories persisted (see online supplementary material S3). A strength of this study is its prospective design, even though we acknowledge that causal inferences from observational studies should be interpreted with greater caution than effects determined in, for example, randomised controlled trials. Thus, observational studies suffer the risk of reversed causality. However, it appears unreasonable that the observed changes in pain during the 12-months follow-up would have caused a higher sitting time during baseline. Also, to account for possible confounding by baseline pain on the association between sitting time and pain trajectories, we did adjust for baseline pain intensity (see online 
supplementary material S3), and found the association to be maintained. This is a strong indication that occupational sitting time affected the course of neckshoulder pain rather than the reversed causation. The stratified analyses by occupational sector should be interpreted with caution due to the reduced sample size; the transportation sector contained only 57 workers, and thus, the models in this stratum were most likely overfitted. Further, the cleaning and transportation sectors differed markedly in gender distribution. Consequently, the effect of sector on the association between sitting and pain trajectories may have been confounded by gender. Still, adjusting for gender and sector in the primary analysis did not change the estimates of the association between sitting and pain trajectories, which indicates that our main findings were not confounded by any of these factors. There is currently a lack of data on within-subject variability in occupational sitting (ie, across days or weeks). The average accelerometry wear time in this study was 2.6 days, while more days may be needed to obtain a more reliable record of sitting exposure. ${ }^{38}$ Given that the observed effect sizes were relatively small, the clinical relevance of our findings may be put into question. The difference between the lower (mean $11 \%$ ) and higher (mean 55\%) tertiles in sitting time at work was $44 \%$ of the working hours, which corresponded to an estimated 12-month reduction in pain intensity of 0.5 units on the 1-10 scale. Further, since our study focused on blue-collar workers, the results are not generalisable to workers in office-based jobs. The association between sitting and neck-shoulder pain was investigated in the whole study population, including even workers without symptoms at baseline, since analyses of subgroups would have led to less representative results and compromised statistical power. Thus, it is of interest to further examine the impact of sitting on neck-shoulder pain in people with more severe chronic pain.

\section{CONCLUSION}

We found that more sitting time at work, as assessed objectively, was associated with a favourable course of neck-shoulder pain intensity over 12 months in bluecollar workers. The relationship between sitting at work and pain needs further investigation before explicit recommendations and guidelines on sedentary behaviour among blue-collar workers can be developed. Future prospective studies with objective assessment of sitting should examine this association further in other populations, such as office workers.

Contributors DMH contributed to the statistical data analyses and drafting of the manuscript. AH and MBJ contributed to the conception and design of the full DPHACTO study, and data collection. All authors contributed to the conception of this study, interpretation of results, and critical revisions of the manuscript; and they all agreed on its final appearance.

Funding The study is partly supported by a grant from the Danish Work Environment Research Fund (04-2014-09).
Competing interests None declared.

\section{Patient consent Obtained.}

Ethics approval The local Ethics Committee in Copenhagen (H-2-2012-011).

Provenance and peer review Not commissioned; externally peer reviewed.

Data sharing statement The DPHACTO data set is available on request (contact: AH, email aho@arbejdsmiljoforskning.dk).

Open Access This is an Open Access article distributed in accordance with the Creative Commons Attribution Non Commercial (CC BY-NC 4.0) license, which permits others to distribute, remix, adapt, build upon this work noncommercially, and license their derivative works on different terms, provided the original work is properly cited and the use is non-commercial. See: http:// creativecommons.org/licenses/by-nc/4.0/

\section{REFERENCES}

1. Côté $P$, van der Velde G, Cassidy JD, et al. The burden and determinants of neck pain in workers: results of the bone and joint decade 2000-2010 task force on neck pain and its associated disorders. J Manipulative Physiol Ther 2009;32:S70-86.

2. Carroll L, Hogg-Johnson S, Côté $P$, et al. Course and prognostic factors for neck pain in workers. Eur Spine J 2008;17:93-100.

3. Ariëns $G$, van Mechelen $W$, Bongers $P$, et al. Physical risk factors for neck pain. Scand J Work Environ Health 2000;26:7-19.

4. Skov T, Borg V, Orhede E. Psychosocial and physical risk factors for musculoskeletal disorders of the neck, shoulders, and lower back in salespeople. Occup Environ Med 1996;53:351-6.

5. Cagnie B, Danneels L, Van Tiggelen D, et al. Individual and work related risk factors for neck pain among office workers: a cross sectional study. Eur Spine J 2007;16:679-86.

6. Yue P, Liu F, Li L. Neck/shoulder pain and low back pain among school teachers in China, prevalence and risk factors. BMC Public Health 2012;12:789.

7. Hallman DM, Gupta N, Mathiassen SE, et al. Association between objectively measured sitting time and neck-shoulder pain among blue-collar workers. Int Arch Occup Environ Health 2015;88: 1031-42.

8. Mayer J, Kraus T, Ochsmann E. Longitudinal evidence for the association between work-related physical exposures and neck and/ or shoulder complaints: a systematic review. Int Arch Occup Environ Health 2012:85:587-603.

9. Lagersted-Olsen J, Korshöj M, Skotte J, et al. Comparison of objectively measured and self-reported time spent sitting. Int J Sports Med 2014;35:534-40.

10. Clark BK, Thorp AA, Winkler EA, et al. Validity of self-reported measures of workplace sitting time and breaks in sitting time. Med Sci Sports Exerc 2011;43:1907-12.

11. Celis-Morales CA, Perez-Bravo F, Ibañez L, et al. Objective vs. self-reported physical activity and sedentary time: effects of measurement method on relationships with risk biomarkers. PLOS ONE 2012;7:e36345.

12. Picavet HSJ, Pas $\mathrm{LW}$, van Oostrom $\mathrm{SH}$, et al. The relation between occupational sitting and mental, cardiometabolic, and musculoskeletal health over a period of 15 years-the Doetinchem Cohort Study. PLoS ONE 2016;11:e0146639.

13. Miranda H, Gold JE, Gore R, et al. Recall of prior musculoskeletal pain. Scand J Work Environ Health 2006;32:294-9.

14. Axén I, Bergström G, Bodin L. Using few and scattered time points for analysis of a variable course of pain can be misleading: an example using weekly text message data. Spine J 2014;14:1454-9.

15. Axén I, Leboeuf-Yde C. Trajectories of low back pain. Best Pract Res Clin Rheumatol 2013;27:601-12.

16. Cudlip AC, Callaghan JP, Dickerson CR. Effects of sitting and standing on upper extremity physical exposures in materials handling tasks. Ergonomics 2015;58:1637-46.

17. O'Sullivan PB, Grahamslaw KM, Kendell M, et al. The effect of different standing and sitting postures on trunk muscle activity in a pain-free population. Spine 2002;27:1238-44.

18. Schüldt K, Ekholm J, Harms-Ringdahl K, et al. Effects of changes in sitting work posture on static neck and shoulder muscle activity. Ergonomics 1986;29:1525-37.

19. Visser B, van Dieën JH. Pathophysiology of upper extremity muscle disorders. J Electromyogr Kinesiol 2006;16:1-16.

20. Hallman DM, Sato T, Kristiansen J, et al. Prolonged sitting is associated with attenuated heart rate variability during sleep in blue-collar workers. Int J Environ Res Public Health 2015;12:14811-27. 
21. Sluka KA, O’Donnell JM, Danielson J, et al. Regular physical activity prevents development of chronic pain and activation of central neurons. J Appl Physiol 2013;114:725-33.

22. Hughson RL, Shoemaker JK. Autonomic responses to exercise: deconditioning/inactivity. Auton Neurosci 2015;188:32-5.

23. Ferretti G, lellamo F, Pizzinelli $P$, et al. Prolonged head down bed rest-induced inactivity impairs tonic autonomic regulation while sparing oscillatory cardiovascular rhythms in healthy humans. J Hypertens 2009;27:551-61.

24. Grooten WJA, Mulder M, Josephson M, et al. The influence of work-related exposures on the prognosis of neck/shoulder pain. Eur Spine J 2007;16:2083-91.

25. Jørgensen MB, Korshøj M, Lagersted-Olsen J, et al. Physical activities at work and risk of musculoskeletal pain and its consequences: protocol for a study with objective field measures among blue-collar workers. BMC Musculoskelet Disord 2013;14:1-9.

26. Hallman DM, Mathiassen SE, Gupta N, et al. Differences between work and leisure in temporal patterns of objectively measured physical activity among blue-collar workers. BMC Public Health 2015;15:976.

27. Gupta N, Christiansen CS, Hallman DM, et al. Is objectively measured sitting time associated with low back pain? PLOS ONE 2015;10:e0121159.

28. Skotte J, Korshøj M, Kristiansen J, et al. Detection of physical activity types using triaxial accelerometers. J Phys Act Health 2014;11:76-84.

29. Stemland I, Ingebrigtsen J, Christiansen CS, et al. Validity of the Acti 4 method for detection of physical activity types in free-living settings: comparison with video analysis. Ergonomics 2015;58:953-65.

30. Ingebrigtsen J, Stemland I, Christiansen CS, et al. Validation of a commercial and custom made accelerometer-based software for step count and frequency during walking and running. J Ergonomics 2013;3:1-6.

31. Korshøj M, Skotte JH, Christiansen CS, et al. Validity of the Acti4 software using ActiGraph GT3X+accelerometer for recording of arm and upper body inclination in simulated work tasks. Ergonomics 2014;57:247-53.

32. Ferreira-Valente MA, Pais-Ribeiro JL, Jensen MP. Validity of four pain intensity rating scales. Pain 2011;152:2399-404.

33. Dworkin RH, Turk DC, Farrar JT, et al. Core outcome measures for chronic pain clinical trials: IMMPACT recommendations. Pain 2005;113:9-19.

34. Tüchsen F, Hannerz H, Burr H. A 12 year prospective study of circulatory disease among Danish shift workers. Occup Environ Med 2006;63:451-5.

35. Pejtersen JH, Kristensen TS, Borg V, et al. The second version of the Copenhagen Psychosocial Questionnaire. Scand J Public Health 2010;38:8-24.

36. West BT, Welch KB, Andrzej TG. Linear mixed models: a practical guide using statistical software: CRC Press, 2014

37. Ariëns GAM, Bongers PM, Douwes $\mathrm{M}$, et al. Are neck flexion, neck rotation, and sitting at work risk factors for neck pain? Results of a prospective cohort study. Occup Environ Med 2001;58:200-7.

38. Aadland E, Ylvisåker E. Reliability of objectively measured sedentary time and physical activity in adults. PLOS ONE 2015;10 e0133296. 